\title{
Influence of biofilm formation on the mechanical properties of enamel after treatment with $\mathrm{CPP}-\mathrm{ACP}$ crème
}

\section{Patrícia Regina Almeida de OLIVEIRA ${ }^{\text {(a) }}$ \\ Thereza Christina Lopes COUTINHO(b) \\ Maristela Barbosa PORTELA(b) \\ Viviane Cancio Andrade de PAULA ${ }^{(b)}$ \\ Mônica Almeida TOSTES ${ }^{(b)}$}

(a) Universidade Federal Fluminense - UFF, School of Dentistry, Nova Friburgo, RJ, Brazil.

(b) Universidade Federal Fluminense - UFF, School of Dentistry, Niterói, RJ, Brazil.

Declaration of Interests: The authors certify that they have no commercial or associative interest that represents a conflict of interest in connection with the manuscript.

\section{Corresponding Author:}

Mônica Almeida Tostes

E-mail: matostesuff@yahoo.com.br

https://doi.org/10.1590/1807-3107BOR-2017.vol31.0084

Submitted: February 10, 2017

Accepted for publication: July 10, 2017

Last revision: August 23, 2017

\begin{abstract}
The study aimed to investigate the effects of bacterial biofilms on changes in the surface microhardness of enamel treated with casein phosphopeptide-amorphous calcium phosphate (CPP-ACP) with and without fluoride. Human enamel blocks with incipient caries-like lesions were divided into four groups of 13: G1: Saliva (Control); G2: fluoride dentifrice (Crest ${ }^{\mathrm{TM}}$, 1100 ppm as NaF); G3: CPP-ACP (MI Paste; Recaldent $^{\mathrm{TM}}$ ); and G4: CPP-ACPF (MI Paste Plus; Recaldent ${ }^{\mathrm{TM}} 900$ ppm as $\mathrm{NaF}$ ). The specimens were soaked in demineralizing solution for $6 \mathrm{~h}$ and remineralized in artificial saliva for $18 \mathrm{~h}$ alternately for 10 days. The dentifrice was prepared with deionized water in a 1:3 ratio $(w / w)$ or applied undiluted in the case of the CPP-ACP group. The surface microhardness $(\mathrm{SMH})$ was evaluated at baseline, after artificial caries, after $\mathrm{pH}$ cycling and treatment with dentifrices, and after incubation in media with Streptococcus mutans for biofilm formation. The biofilms were exposed once a day to $2 \%$ sucrose and the biofilm viability was measured by MTT reduction. The percentage of change in surface microhardness (\%SMHC) was calculated for each block. The data were analyzed by nonparametric test comparisons $(\alpha=0.05)$. The \%SMHC values observed in G2 were different from those of G1, G3, and G4 ( $p<0.05)$. After biofilm formation, \%SMHC was positive in G2 and G4 when compared to G1 and G3, but resistance to demineralization after biofilm formation was similar in all groups. In conclusion, the presence of biofilms did not influence the treatment outcomes of anticaries products.
\end{abstract}

Keywords: Dental Caries; Hardness Test; Fluorides; Caseins; Dentifrices.

\section{Introduction}

Dental caries is initiated by acid-producing bacteria on dental biofilms, which cause carious lesions in the presence of fermentable carbohydrates. Dental biofilms play a crucial role in cariogenesis. They do not only function as acid producers during caries formation, but they may also serve as reservoirs and diffusion barriers for caries-preventive components. ${ }^{1}$ Several novel remineralization agents, including casein phosphopeptide-amorphous calcium phosphate (CPP-ACP) nanocomplexes, have shown great anticaries potential. ${ }^{2,3,4,5} \mathrm{CPP}$-calcium phosphate complexes are anticariogenic and capable of remineralizing the early stages of enamel lesions in in situ and in vivo studies. ${ }^{3,46}$ The beneficial effect obtained with CPP-ACP is associated 
with the ability to localize calcium and phosphate on dental biofilm close to the tooth, thus making it available when needed. In the presence of an acidic environment, such as after eating, when the $\mathrm{pH}$ of the mouth decreases, casein phosphopeptide proteins release amorphous calcium and phosphate, creating a supersaturated state of calcium and phosphate around the tooth. During a cariogenic challenge, fluoride, calcium, and phosphate present on the biofilm may diffuse into the enamel, promoting remineralization. ${ }^{6}$ In addition, significantly high levels of calcium and phosphate have been found in both biofilm and subsurface incipient carious lesions and in lower level demineralization of enamel or dentin surfaces previously treated with CPP-ACP-based compounds. ${ }^{7}$ In terms of its mechanism of action, it has been suggested that the presence of the CPP-ACP agent delays biofilm formation and favors nucleation and crystallization of calcium phosphates, possibly in the form of apatite, in mature biofilms. ${ }^{8}$

Remineralized enamel treated with fluoride and CPP-ACP can be more resistant to a new cariogenic attack. Thus, Ekassas and Arafa ${ }^{9}$ and Piagnatelli et al. ${ }^{10}$ determined the stability of remineralized surfaces treated with CPP-ACP against acid attack and, therefore, a second sequence of demineralization was used to assess the stability of the newly formed precipitate. Furthermore, following the exposure to acid challenge, partial dissolution of the coating layer was evident with the existence of a demineralized surface, but CPP-ACPF, fTCP, and ACPF presented significantly higher resistance to softening than did the control. ${ }^{9}$ In another study, Piagnatelli et al. ${ }^{10}$ showed that fluoride dentifrice offers fast remineralization when compared to CPP-ACP, but the precipitates formed following its application dissolved 2.7 times faster than those formed by CPP-ACP.

$\mathrm{pH}$-cycling models are chemical models that are not able to estimate the antimicrobial effect of fluoride or other substances on caries. ${ }^{1,11,12}$ Thus, biofilm models have been used to evaluate the in vitro effect of toothpastes containing antimicrobial compounds such as fluoride on Streptococcus mutans biofilm formation. ${ }^{12}$

Therefore, the aim of this in vitro study was to evaluate the effect of biofilm formation on surfaces treated with CPP-ACP and CPP-ACPF on enamel demineralization when compared to controls (fluoride dentifrice and no treatment). The null hypothesis was that the treatment of enamel surface with CPP-ACP and CPP-ACPF topical crème would not significantly reduce enamel surface microhardness following biofilm formation when compared to controls.

\section{Materials and Methods}

\section{Sample preparation}

In this study, 35 human third molar teeth, which had been extracted for surgical reasons, were used. This study was approved by the Medical Sciences Research Ethics Committee, Fluminense Federal University (process no. 580.849). The samples presented caries-free, fluorotic, or hypomineralized lesions and any other visible defects. The teeth were stored in $0.1 \%$ thymol during sample preparation. Four enamel blocks were obtained from each tooth. After embedding the blocks in acrylic resin, the buccal and lingual surfaces of the enamel specimens $(2 \mathrm{~mm} \times$ $2 \mathrm{~mm} \times 2 \mathrm{~mm}$ ) were ground with $\mathrm{SiC}$ paper (400, 600 and 1,200 grit) (Struers S/A, Ballerup, Denmark) in order to obtain flat surfaces. The specimens were then polished using a 1- $\mu \mathrm{m}$ diamond polishing suspension with a polishing cloth (Arotec Ind \& Com, Cotia, SP, Brazil). The surface hardness was measured using a 2001 MicroMet microhardness tester (Buehler, Lake Bluff, USA) with a Knoop indenter, and with a static load of $25 \mathrm{~g}$ for $15 \mathrm{~s}$. The Knoop hardness number $(\mathrm{KHN})$ was calculated from the length of the indentation and the applied load. An increase in length in $\mu \mathrm{m}$ indicates softening of the enamel due to demineralization. Five indentations separated by a $100-\mu \mathrm{m}$ distance were made in the central region of each block $\left(\mathrm{SMH}_{\text {baseline }}\right)$. The average of the five indentations made on each specimen was used as the $\mathrm{SMH}$ baseline value $\left(\mathrm{SMH}_{\text {baseline }}\right)$. After $\mathrm{SMH}_{\text {baseline }}$ measurements, 52 enamel blocks were selected, with a KHN ranging from 289.7 to 399.7. ${ }^{13}$

The KHN was used to monitor enamel surfaces in three phases: Phase 1: artificial caries; Phase 2: $\mathrm{pH}$ cycling and treatment with dentifrices; and Phase 3 : demineralization with $S$. mutans biofilm formation on the newly treated surface (Figure 1). 


\section{Phase 1 - artificial caries}

Each enamel block was immersed in $10 \mathrm{~mL}$ of a demineralizing solution for $72 \mathrm{~h}\left(2 \mathrm{mMCa}\left(\mathrm{Ca}\left(\mathrm{NO}_{3}\right)\right)_{2}\right.$, $2 \mathrm{mM} \mathrm{PO}_{4}\left(\mathrm{KH}_{2} \mathrm{PO}_{4}\right)$, and $75 \mathrm{mM}$ of acetate at $\left.4.3 \mathrm{pH}\right)^{13}$ and washed at the end in distilled water for $1 \mathrm{~min}$. This demineralizing solution was used for both the $\mathrm{pH}$-cycling model (demineralization) and caries-like lesion formation on enamel blocks. ${ }^{13}$ The exposed area was $2 \mathrm{~mm}$ long (y axis) and $2 \mathrm{~mm}$ wide (x axis). After induction of artificial caries, five other indentations were made at $100 \mu \mathrm{m}$ from the $\mathrm{SMH}_{\text {baseline. }}$. As described previously, the averages obtained from each sample were used as the enamel treatment value, $\mathrm{SMH}_{\text {phasel }}$.

\section{Phase 2 - pH cycling and treatment with dentifrices}

The enamel blocks were distributed into four groups of 13 blocks each: Group 1: Control; Saliva; Group 2: FD Crest ${ }^{\mathrm{TM}}$ Cavity Protection (1,100 ppm F as NaF, Procter \& Gamble), used as a positive control; Group 3: CPP-ACP (MI Paste; Recaldent ${ }^{\text {TM }}$ GC Corporation Tokyo, Japan); and Group 4: CPP-ACPF (MI Paste Plus; Recaldent ${ }^{\text {TM }}$ 900 ppm as NaF, GC Corporation Tokyo, Japan). The formulations of each product are described in Table1. The enamel blocks were subjected to four $\mathrm{pH}$ cycles/day for 10 days, at $37^{\circ} \mathrm{C}$ (Figure 1). After sonication and rinsing with distilled water, the specimens were immersed separately in $10 \mathrm{~mL}$ of demineralizing solution $(8-10 \mathrm{~h}$, 12-14 h, 16-18 h), and in the remaining hours (18 h/day) they were transferred to an artificial saliva solution $(10 \mathrm{~mL})$. Standard $\mathrm{pH}$-cycling conditions were used in a daily schedule of three cycles ( $2 \mathrm{~h}$ of demineralization and $2 \mathrm{~h}$ of remineralization each, followed by a period in artificial saliva $(6 \mathrm{~h}$ in demineralizing solution and $18 \mathrm{~h}$ in saliva). The artificial saliva was replaced daily and consisted of $0.67 \mathrm{~g} / \mathrm{L} \mathrm{NaCl} ; 0.1168 \mathrm{~g} / \mathrm{L} \mathrm{CaCl}_{2} ; 8 \mathrm{~g} / \mathrm{L}$ $\mathrm{CMC} ; 0.0408 \mathrm{~g} / \mathrm{L} \mathrm{MgCl}_{2} ; 0.96 \mathrm{~g} / \mathrm{L} \mathrm{KCl} ; 1 \mathrm{~g} / \mathrm{L} \mathrm{C}_{8} \mathrm{H}_{8} \mathrm{O}_{3} ; 24$ $\mathrm{g} / \mathrm{LC}_{6} \mathrm{H}_{14} \mathrm{O}_{6} ; 964.938 \mathrm{~mL} / \mathrm{LH}_{2} \mathrm{O}$ and $0.274 \mathrm{~g} / \mathrm{L} \mathrm{KH}_{2} \mathrm{PO}_{4}$. In each transfer between the different solutions, the enamel specimens were rinsed in distilled water for 1 min at $37^{\circ} \mathrm{C}$. The fluoride dentifrice (G2) was applied in a slurry at a dentifrice to deionized water ratio of 1:3 for $60 \mathrm{~s}$. A standardized volume $(0.15 \mathrm{~mL})$ was applied to each sample using a syringe. The treatment was carried out before the first, second, and third demineralization cycles. Specimens in the CPP-ACP and CPP-CPF (G3 and G4) groups received a topical application $(0.03 \mathrm{~g})$ on their surface for the same amount of time. ${ }^{13}$ The negative control (Group 1) was only subjected to the cariogenic challenge. After the last demineralization challenge, the enamel specimens were rinsed in distilled water for 1 min and then immersed in $10 \mathrm{~mL}$ of artificial saliva. The solutions were changed every day. As described previously, five indentations were made and the averages

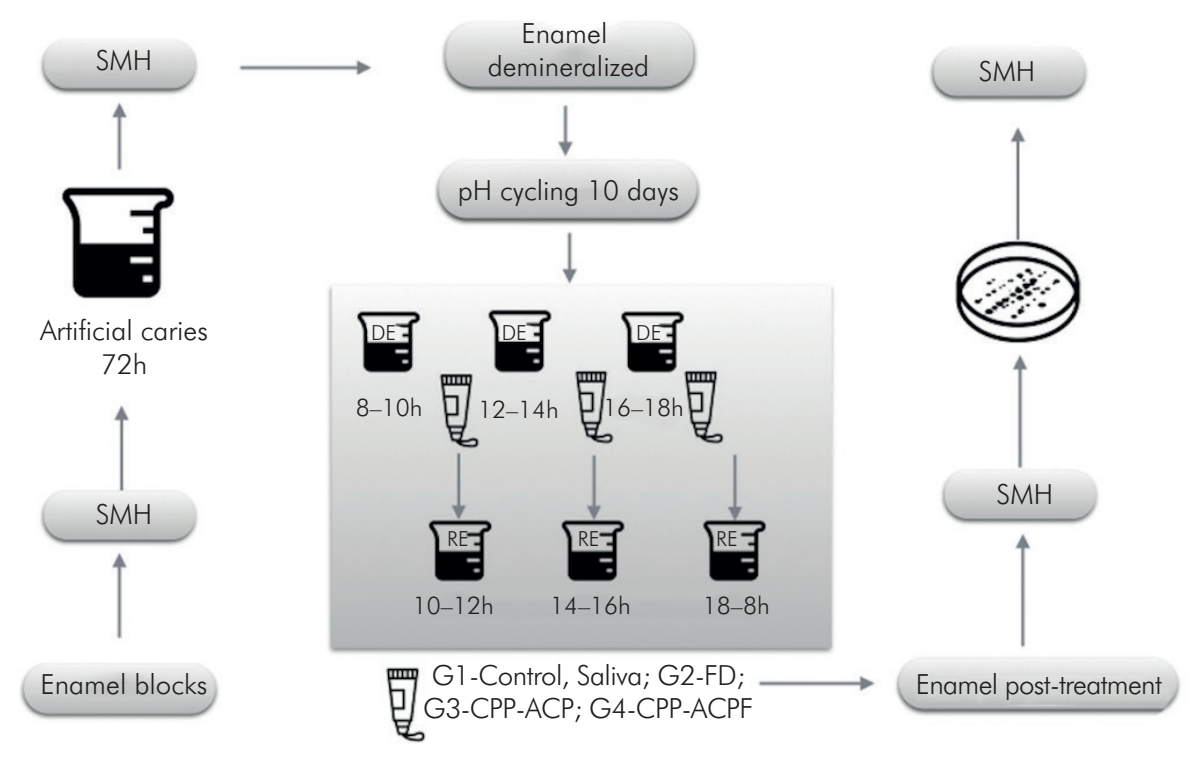

Figure 1. Schematic illustration of the procedure used in $\mathrm{pH}$ cycling and remineralization treatment. 
obtained from each sample were used as the enamel treatment value, $\mathrm{SMH}_{\text {phaser. }}$. The indentations were made at a distance of $100 \mu \mathrm{m}$ from the $\mathrm{SMH}_{\text {phasel }}$.

\section{Phase 3 - Streptococcus mutans biofilm formation}

In this phase, the samples subjected to Phases 1 and 2 were placed in 24-well plates (TPP, 24 Zellkultur Testplatte F) and sterilized by ethylene oxide. The mature biofilm was then formed by $S$. mutans, which is a cariogenic bacterium and the primary causative agent of caries.

Briefly, S. mutans ATCC 25175 (American Type Culture Collection, Fiocruz, Rio de Janeiro, RJ, Brazil) was cultured overnight in brain heart infusion (BHI, Difco, Sparks, MD, USA) broth at $37^{\circ} \mathrm{C}$ under anaerobic conditions. The bacterial inoculum was adjusted to an optical density (OD) of 0.5 at $550 \mathrm{~nm}$ in accordance with the McFarland standard. The bacterial suspension was diluted 1:100 and then $10 \mu \mathrm{L}$ was inoculated into each well with BHI supplemented with $2 \%$ sucrose. ${ }^{14}$ The 24-well plates were then incubated at $37^{\circ} \mathrm{C}$ under anaerobic conditions for $48 \mathrm{~h}$. During the 2 days of biofilm formation, the growth medium was changed every $24 \mathrm{~h}$. The biofilm formed on the specimens was used in the subsequent experiments.

\section{Metabolic activity of Streptococcus mutans biofilms}

At the end of biofilm formation, the metabolic activity of $S$. mutans biofilms formed on the enamel specimens was analyzed by thiazolyl blue tetrazolium bromide (MTT, Sigma Aldrich, St. Louis, MO, USA) reduction assay. ${ }^{14,15} \mathrm{MTT}$ is a colorimetric assay that measures the enzymatic reduction of MTT, a yellow tetrazole, to purple formazan. The specimens were transferred to microtubes with $1 \mathrm{~mL}$ of sterile saline solution $(\mathrm{NaCl} 0.85 \%)$ and the biofilms were removed by vortex mixing for three 1-minute periods. After that, the enamel specimens were removed for future analysis and the $S$. mutans suspensions were centrifuged for cell separation. Then, $100 \mu \mathrm{L}$ of sterile MTT ( $1 \mathrm{mg} / \mathrm{mL}$ in PBS) was added to each microtube with biofilm cells and incubated at $37^{\circ} \mathrm{C}$ under anaerobic conditions for $1 \mathrm{~h}$. Then, $100 \mu \mathrm{L}$ of dimethyl sulfoxide (DMSO) was added to each microtube, which were incubated for $20 \mathrm{~min}$ at room temperature in the dark and with gentle agitation. The DMSO solutions were placed in a microplate reader at $540 \mathrm{~nm}$. A higher absorbance is related to a higher formazan concentration, which indicates higher metabolic activity of the biofilm. ${ }^{14}$ The results were calculated as OD units.

After that, five indentations were made and the averages obtained from each sample were used as the enamel treatment value, $\mathrm{SMH}_{\text {phase3 }}$. The indentations were made at a distance of $100 \mu \mathrm{m}$ from the $\mathrm{SMH}_{\text {phase22 }}$.

\section{Determination of changes in surface microhardness (\%SMHC)}

Enamel SMH was measured at baseline in sound untreated enamel after artificial caries induction (Phase 1), after $\mathrm{pH}$ cycling and remineralization (Phase 2), and after biofilm formation (Phase 3). The percentage change of $\mathrm{SMH}$ (\%SMHC) was calculated by $\left[\% \mathrm{SMHC}_{\text {phase2 }}=100 \times\left(\mathrm{SMH}_{\text {phase2 }}-\mathrm{SMH}_{\text {phase1 }}\right) /\right.$ $\left.\mathrm{SMH}_{\text {phasee }}\right]$ and $\left[\% \mathrm{SMHC}_{\text {phase3 }}=100 \times\left(\mathrm{SMH}_{\text {phase3 }}-\right.\right.$ $\left.\left.\mathrm{SMH}_{\text {phase2 } 2}\right) / \mathrm{SMH}_{\text {phase } 2}\right]$.

Table 1. Tested products and their respective composition.

\begin{tabular}{|c|c|}
\hline Product & Composition* \\
\hline MI Paste & $\begin{array}{c}\text { Pure water, glycerol, 10\% per weight of CPP-ACP, D-sorbitol, CMC-Na, propylene glycol, silicon dioxide, titanium } \\
\text { dioxide, xylitol, phosphoric acid, flavoring, zinc oxide, sodium saccharin, ethyl p-hydroxybenzoate, magnesium } \\
\text { oxide, guar gum, propyl p-hydroxybenzoate, butyl p-hydroxybenzoate }\end{array}$ \\
\hline MI Paste Plus & $\begin{array}{l}\text { Pure water, glycerol, 10\% per weight of CPP-ACP, D-sorbitol, CMC-Na, propylene glycol, silicon dioxide, titanium } \\
\text { dioxide, xylitol, phosphoric acid, sodium fluoride, flavoring, sodium saccharin, ethyl p-hydroxybenzoate, propyl } \\
\text { p-hydroxybenzoate, butyl p-hydroxybenzoate }\end{array}$ \\
\hline Crest Cavity Protection & $\begin{array}{l}\text { Sodium fluoride } 0.243 \% \text { ( } 0.15 \% \text { w/v fluoride ion), sorbitol, water, hydrated silica, sodium lauryl sulfate, trisodium } \\
\text { phosphate, flavoring, sodium phosphate, cellulose gum, carbomer } 956 \text {, sodium saccharin, titanium dioxide, blue } 1\end{array}$ \\
\hline
\end{tabular}

*Information provided by the manufacturer. 


\section{Statistical analysis}

The data were analyzed using the SPSS statistical software package for Windows, version 20.0 (IBM Corporation, New York, NY, USA). Initially, all data $\left(\mathrm{SMH}_{\text {baseline, }}, \mathrm{SMH}_{\text {phase1}}, \mathrm{SMH}_{\text {phase }}, \mathrm{SMH}_{\text {phase3, }}\right.$ and \%SMHC) were checked by the Shapiro-Wilk test and Levene's test. Based on these preliminary analyses, the $\mathrm{SMH}_{\text {phase1 }}, \mathrm{SMH}_{\text {phase2 }}$ and $\mathrm{SMH}_{\text {phase3 }}$ data were subjected to one-way analysis of variance and Tukey's HSD post-hoc test and the \%SMHC data were analyzed by the Kruskal Wallis and Mann-Whitney tests. \%SMHC before and after treatment in the same group was analyzed using Student's $t$-test. All analyses were performed at a significance level of $a=0.05$.

\section{Results}

The mean and standard deviation for the SMH (KHN) for the study groups and phases are presented in Table 2. The pH-cycling model utilized in this study demonstrated the ability to demineralize the tooth surface. The specimens demonstrated a significant decrease in microhardness after treatment (Student's $t$-test $\mathrm{p}<0.05)$. One-way ANOVA showed a statistically significant difference in the mean enamel SMH between the groups in phases 2 and $3(\mathrm{p}<0.05)$, with a higher mean $\mathrm{SMH}$ value in the group that was treated with 1100 ppm F dentifrice $(\mathrm{p}<0.05)$.

After treatment, G2 (FD) showed lower demineralization (\%SMHC) than G1 (Saliva), G3 (CPP-ACP), and G4 (CPP-ACPF) (Kruskal Wallis; $\mathrm{p}<0.05)$. G1, G3 and, G4 had similar outcomes (Figure 2; Mann-Whitney; $p>0.05)$. Hardness $(p<0.05)$ increased in G2 and G3; however, no significant differences were found among the four test groups (Kruskal-Wallis; p > 0.05).

Finally, regarding biofilm formation and metabolic activity of $S$. mutans biofilms for 2 days, no differences were observed among the studied dentifrices (Kruskal-Wallis; $\mathrm{p}>0.05$ ). At 48 h of incubation, G1 $(0.16 ; 95 \% \mathrm{CI}=0.12-0.20)$ and G2 $(0.17 ; 95 \% \mathrm{CI}=0.15-0.19)$ showed a lower but not significant reduction in the metabolic activity of the biofilm formed compared with G4 (0.18; $95 \% \mathrm{CI}=0.17-0.19)$ and $\mathrm{G} 3(0.18 ; 95 \% \mathrm{CI}=0.17-0.26)$ (Table 3; Kruskal-Wallis; $\mathrm{p}<0.05$ ).

\section{Discussion}

The purpose of this study was to evaluate the remineralization efficacy of CPP-ACP with and without fluoride in artificial caries-like enamel lesions. To determine the stability of the treated surface against acid attack, a second demineralization sequence was performed to assess the stability of the newly formed precipitate with $S$. mutans biofilm formation.

This study was carried out in three phases. In the second phase, the demineralized enamel blocks were underwent $\mathrm{pH}$ cycling, and in the third phase, S. mutans biofilm formation was used to evaluate the metabolic activity of the biofilm formed on enamel treated with fluoride dentifrice, $\mathrm{CPP}-\mathrm{ACP}$, and $\mathrm{CPP}-\mathrm{ACPF}$ crème during $\mathrm{pH}$ cycling. Changes in theenamel were evaluated by assessing $\mathrm{SMH} .{ }^{9,11,13,16,17}$ Microhardness indentation measurements can provide indirect evidence of mineral loss or gain. The drawback with the technique $(\mathrm{SMH})$ used in the study is that it cannot quantify the amount

Table 2. Mean $\pm S D$ for sound enamel $\left(S M H_{\text {baseline }}\right)$, artificial caries $\left(S M H_{\text {phase }}\right)$, post-treatment $\left(S M H_{\text {phase } 2}\right)$, and post-biofilm $\left(S M H_{\text {phase } 3}\right)$ surfaces in various experimental phases. $\mathrm{n}=13$

\begin{tabular}{lcccc}
\hline \multirow{2}{*}{ Groups } & \multicolumn{3}{c}{ SMH (KHN) } \\
\cline { 2 - 5 } & Baseline & Phase 1 & Phase 2 & Phase 3 \\
\hline G1(saliva) & $351.2 \pm 20^{\mathrm{aA}}$ & $301.1 \pm 23^{\mathrm{aB}}$ & $37.2 \pm 15^{\mathrm{bC}}$ & $30.7 \pm 17^{\mathrm{bC}}$ \\
G2(FD) & $330.5 \pm 49^{\mathrm{aA}}$ & $294.5 \pm 43^{\mathrm{aB}}$ & $98.1 \pm 18^{\mathrm{aC}}$ & $103.1 \pm 32^{\mathrm{aC}}$ \\
G3(CPP-ACP) & $318.5 \pm 47^{\mathrm{aA}}$ & $266.4 \pm 53^{\mathrm{aB}}$ & $42.6 \pm 25^{\mathrm{bC}}$ & $43,3 \pm 30^{\mathrm{bC}}$ \\
G4 (CPP-ACPF) & $333.1 \pm 39^{\mathrm{aA}}$ & $279.9 \pm 57^{\mathrm{aB}}$ & $42.0 \pm 26^{\mathrm{bC}}$ & $41.0 \pm 15^{\mathrm{bC}}$ \\
\hline
\end{tabular}

Different uppercase and superscript lowercase letters indicate significant difference between tested groups at $p<0.05$ (ANOVA and Tukey's HSD post-hoc test). Superscript lowercase letters are used for comparison within the same column and uppercase letters are used for comparison within each row. Comparison before and after treatment in the same group was analyzed by Student's $t$-test. 


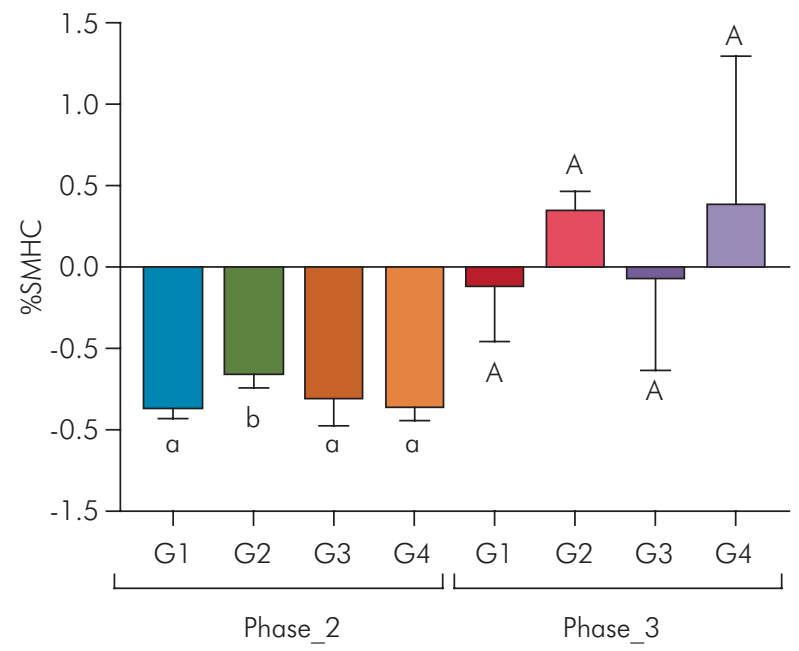

Figure 2. Percentage surface hardness change (\%SMHC) for each experimental group. Results are expressed as means and standard deviations (SD). Same lowercase letters (phase 2) and uppercase letters (phase 3) indicate no significant differences amongst the values (Kruskal-Wallis and Mann-Whitney tests; $\mathrm{p}<0.05)$. G1 (Saliva); G2 (FD); G3 (CPP-ACP), and G4 (CPP-ACPF).

Table 3. Metabolic activity of biofilm formation on enamel surfaces after $48 \mathrm{~h}$ of incubation (phase 3) measured by MTT reduction assay. G1 (Saliva); G2 (FD); G3 (CPP-ACP), and G4 (CPP-ACPF). Median values and confidence interval (Cl); Kruskal-Wallis; $p>0.05$.

\begin{tabular}{lcccc}
\hline Variable & G1 & G2 & G3 & G4 \\
\hline $\begin{array}{l}\text { Biofilm } \\
\text { metabolic }\end{array}$ & $0.16^{a}$ & $0.17^{a}$ & $0.18^{a}$ & $0.18^{a}$ \\
$\begin{array}{l}\text { activity }\left(\mathrm{A}_{540}\right) \\
95 \% \mathrm{Cl}\end{array}$ & $0.12-0.20$ & $0.15-0.19$ & $0.17-0.20$ & $0.17-0.19$ \\
\hline
\end{tabular}

Values with same superscript lowercase letter are statistically similar $(p>0.05)$

of mineral loss or gain; however, it is very sensitive to changes in mineral density. ${ }^{18}$ The standardization of enamel KHN in artificial caries allowed establishing the \%SMHC among the groups after treatment (Souza et al., ${ }^{17}$ Oliveira et al., ${ }^{13}$ Fernández et al. ${ }^{11}$ ). As an indicator of enamel mineral loss or gain, surface hardness has been widely employed for shallow lesions.,11,13,16,17,1,19

The \%SMHC (phase 2) values obtained after using FD (G2) differed from those observed in the saliva (G1), CPP-ACP (G3), and CPP-ACPF (G4) groups ( $\mathrm{p}<0.05)$. The results of our study are consistent with prior studies conducted by Pulido et al., ${ }^{20}$ Kumar et al., ${ }^{21}$ and Oliveira et al. ${ }^{13}$ where CPP-ACP induced significantly less remineralization compared to FD. Pulido et al. ${ }^{20}$ suggested that a longer CPP-ACP application time may be necessary to find remineralization when CPP-ACP is used. In fact, Souza et al. ${ }^{17}$ observed that increasing the frequency of CPP-ACP application inhibits more demineralization at cyclic $\mathrm{pH}$. In their study, CPP-ACP crème was applied five times a day in the form of a slurry made from $1 \mathrm{~g}$ of CPP-ACP in $3 \mathrm{~mL}$ of distilled deionized water. The results found may be due to methodological differences. However, regarding CPPACPF, previous studies showed that CPP-ACPF has better remineralization effects than saliva, ${ }^{9,13}$ or distilled water. ${ }^{22}$ SMH and \%SMHC did not differ between CPP-ACP and CPP-ACPF, being in agreement with the results of Oliveira et al..$^{13}$ and Hamba et al. ${ }^{22}$ These results may be due to the presence of the fluoride ion in CPP-ACPF, which could interact with the $\mathrm{ACP}$ component of the casein complex, rendering both inorganic components ineffective, or due to saturation of the medium. ${ }^{17,19}$ In addition, the efficacy of CPP-ACP may be influenced by saturation of saliva, ${ }^{13,23}$ time of application, ${ }^{17,22,24}$ or by biofilm formation. ${ }^{3}$ However, in the presence of CPP, which prevents rapid transformation of the calcium phosphate phases, the ions would be stabilized and maintained such that molecules would spontaneously move from a region of higher concentration to one of lower concentration in the subsurface lesion. ${ }^{4}$ In fact, microradiography of the remineralized lesions demonstrated that the fluoride dentifrice (1100 ppm F) remineralized predominantly in the surface layer, whereas the $2 \%$ CPP-ACP dentifrice produced morehomogenous remineralization throughout the body of the lesion. ${ }^{4}$

Few data are available in the literature on the resistance of surfaces treated with CPP-ACP with and without fluoride. ${ }^{4,9,10,22}$ The resistance of the precipitate formed after the application of remineralizing agents has been obtained in in vitro studies with demineralizing solutions. ${ }^{4,9,10,22}$ In this study, the S. mutans biofilm was used with this purpose. The model has been validated recently, enabling the assessment of anticaries effects of fluoride on demineralization of dental substrates and also analyzing the effect of treatments on the biofilm. ${ }^{11}$ S. mutans biofilm formation after $48 \mathrm{~h}$ of incubation in the presence of sucrose was assessed using the MTT assay, which is an indirect biochemical assay 
and a good evaluation of viable bacteria. ${ }^{14,15}$ So, MTT results demonstrate the metabolic activity of the viable cells present in the biofilm. Additionally, in the presence of sucrose, it is possible to assume that the more viable bacteria in the biofilm, the greater the acid production.

During $\mathrm{pH}$ cycling and remineralization treatment, loss of hardness was significantly lower in the FD group (phase 2), whereas no difference was found between phases 2 and 3 (Table 2) after biofilm formation. Thus, G1, G3, and G4 showed significant demineralization (phase 2), but the deposited material provided similar protection after biofilm formation. In addition, following the exposure to $S$. mutans biofilm, \%SMHC (phase 3) was positive only in G2 and G4, but did not differ in comparison with the other groups $(\mathrm{p}<0.05)$. The \%SMHC results were consistent with the concentration of fluoride in the product (G2 and G4), which is an indicator of the effect of fluoride in demineralization and remineralization. In our model, the biofilm was treated once a day with $2 \%$ sucrose; therefore, the protocol may have benefited remineralization and this partially justifies the observed results. In these favorable conditions for remineralization (phase 3), no difference was found between the groups, regardless of the difference in hardness (phase 2). With this biofilm model, we were not able to show that the presence of a biofilm greatly affected the resistance of the precipitate formed after treatment with remineralizing agents.

The role of fluoride in the remineralization process was found to be rather complex. Fluoride acts by inhibiting mineral loss on the crystal surface and by enhancing the reconstruction or calcium and phosphate remineralization in a form that is more resistant to subsequent acid attack. ${ }^{18,26}$ The increased mineral levels observed from \%SMHC in G2 and G4, especially those exposed to 1,100 ppm F, were supported by the highest fluoride incorporation into enamel found in these groups in the second phase. In addition, enamel treated with fluoride has been associated with higher saturation than of fluorapatite and more mineral forms precipitated on the enamel surface. ${ }^{25}$ Subsequent acid challenges must be very strong and long enough to dissolve the remineralized enamel. ${ }^{26,27}$ In addition, although none of the groups differed in terms of microhardness, it seems that the enamel treated with CPP-ACP and FD produced a reservoir of fluoride ions available for inhibiting future demineralization processes. Under such conditions, the enamel could have been enriched with fluoride (G2 and G4) due to precipitation of fluoride apatite in enamel during de-remineralization and dentifrice treatment (phase 2). ${ }^{25,26,27}$

The effect of CPP-ACPF products on the enamel surface had previously been shown to be superior after demineralization when compared to saliva. ${ }^{9}$ The greater protection against demineralization by CPP-ACPF when compared to CPP-ACP has been noted. ${ }^{22}$ In the current study, despite the presence of fluoride in the CPP-ACPF product, both remineralizing agents examined showed similar \%SMHC after phases 2 and 3. In CPP-ACP technology, ACP is stabilized by CPP casein-derived peptides. CPP contains the amino acid cluster sequence -Ser(P)-Ser(P)-Ser(P)-GluGlu - and this has been reported to bind amorphous calcium phosphate, forming small clusters of casein phosphopeptide-amorphous calcium phosphate (CPP-ACP). ${ }^{4}$ Thus, the surface formed after the use of CPP-ACP is different from that formed only in the presence of fluoride dentifrice. ${ }^{4,10,13,17}$ According to Zhang et al., ${ }^{28}$ numerous particles and amorphous crystals were arranged on the surface in the $\mathrm{NaF}$ group, but in the CPP-ACP group, those crystals seemed to be more homogeneous than those in the NaF group, and there was no obvious intercrystalline space. So, dissolution of the new precipitate formed during remineralization by the CPP-ACP product is far more resistant to acid attack. ${ }^{9,10,22}$ The precipitates formed by the CCP-ACP product were found to demineralize 2.7 times slower than those produced by the fluoride dentifrice $(1.1 \%$ $\mathrm{NaF}) \cdot{ }^{10}$ In addition, the residual remineralization after acid challenge was significantly greater for the dentifrice containing CPP-ACP plus 1100 ppm fluoride when compared with $\mathrm{NaF}$ alone. ${ }^{4}$

FD and CPP-ACPF treatments did lead to observable remineralization of the demineralized enamel, but the metabolic activity of the biofilm was the same in all groups ( $p>0.05)$. This result was quite different from that of a previous report, which revealed fluoride treatment could significantly reduce the metabolic activity of biofilms compared with the control group. ${ }^{12}$ 
However, our model differs from previous biofilm models, where biofilm formation was assayed after a 2-minute application of dentifrice to rigid surface enamel without $\mathrm{pH}$ cycling ${ }^{12}$ and formation of biofilm before $\mathrm{pH}$ cycling. ${ }^{1}$ So, precipitation on enamel after application of remineralizing agents can be different and influence metabolic activity.

The SMH result after FD treatment was superior to that of the other groups in both phases (2 and 3), but the metabolic activity of the $S$. mutans biofilm on the enamel specimens did not differ between groups. Nevertheless, in contrast to the observations of Brambilla et al., ${ }^{12}$ our results demonstrated that enamel specimen treatment with fluoride cannot inhibit the metabolic activity of $S$. mutans biofilm, but it can change the diffusion of ions. ${ }^{1}$ Additionally, although the amount of acid produced by this biofilm was not measured, all enamel specimens underwent the same cariogenic challenge generated by the $S$. mutans biofilm in vitro (phase 3). So, $\mathrm{pH}$ assessment could help clarify the results. However, in a recent study, the $\mathrm{pH}$ value of the culture medium, used as an indicator of biofilm acidogenicity, decreased after daily sucrose exposure, but no differences were observed among treatments. ${ }^{11}$

Further studies are needed to evaluate our hypothesis of the metabolic activity of $S$. mutans biofilm and its interference with resistance to demineralization in enamel treated with remineralizing agents. To achieve that, an important step will be the quantification of the acids produced by this biofilm induced in vitro. In addition, according to Zhang et al., ${ }^{1}$ biofilms might act as diffusion barriers to slow the influx of acid and outflux of calcium and phosphate released from the enamel surfaces, resulting in protection of the underlying demineralized enamel. ${ }^{1}$ So, analysis of calcium and fluoride concentrations could also be useful. ${ }^{11}$

Another limitation of the present study could be the use of monospecific biofilm; however, experimental studies have already demonstrated that the amount of lactic acid produced in vitro by polymicrobial biofilms is very similar to that produced by $S$. mutans biofilms alone. ${ }^{29}$

\section{Conclusion}

We conclude that the CPP-ACP and CPPACPF tested in this in vitro study do not prevent demineralization in human enamel. Furthermore, there were no significant differences in microhardness in enamel treated with FD (1100), CPP-ACP, and CPP-ACPF after biofilm formation. Therefore, the presence of biofilms clearly does not influence the treatment outcomes of $\mathrm{CPP}-\mathrm{ACP}$ products. Thus, the null hypothesis was accepted.

\section{Acknowledgments}

The authors would like to thank José Maria Suhett de Azevedo for his laboratory assistance. This paper is based on a thesis submitted by the first author to the School of Dentistry, Fluminense Federal University, in partial fulfillment of the requirements for the Master's Program in Dental Clinics. They also thank the Brazilian Federal Agency for Support and Evaluation of Higher Education for the award of a scholarship to the first author. Funders had no role in study design, data collection and analysis, decision to publish, or preparation of the manuscript.

\section{References}

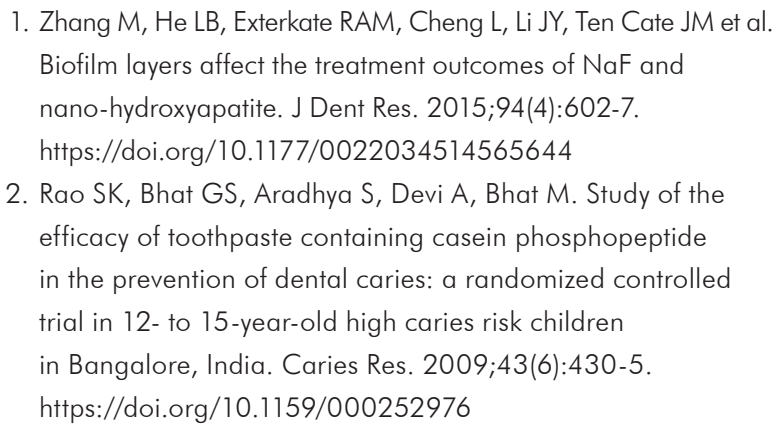

3. Shen P, Manton DJ, Cochrane NJ, Walker GD, Yuan Y, Reynolds $C$ et al. Effect of added calcium phosphate on enamel remineralization by fluoride in a randomized controlled in situ trial. J Dent. 2011;39(7):518-25. https://doi.org/10.1016/i.jdent.2011.05.002

4. Reynolds EC, Cai F, Cochrane NJ, Shen P, Walker GD, Morgan MV et al. Fluoride and casein phosphopeptide-amorphous calcium phosphate. J Dent Res. 2008;87(4):344-8. https://doi.org/10.1177/154405910808700420 
5. Robertson MA, Kau CH, English JD, Lee RP, Powers J, Nguyen JT. MI Paste Plus to prevent demineralization in orthodontic patients: a prospective randomized controlled trial. Am J Orthod Dentofacial Orthop. 2011;140(5):660-8. https://doi.org/10.1016/i.ajodo.2010.10.025

6. Cochrane NJ, Cai F, Huq NL, Burrow MF, Reynolds EC. New approaches to enhanced remineralization of tooth enamel. J Dent Res. 2010;89(11):1187-97. https://doi.org/10.1177/0022034510376046

7. Llena C, Forner L, Baca P. Anticariogenicity of casein phosphopeptide-amorphous calcium phosphate: a review of the literature. J Contemp Dent Pract. 2009;10(3):1-9.

8. Rahiotis C, Vougiouklakis G, Eliades G. Characterization of oral films formed in the presence of a CPP-ACP agent: an in situ study. J Dent. 2008;36(4):272-80. https://doi.org/10.1016/i.jdent.2008.01.005

9. Elkassas D, Arafa A. Remineralizing efficacy of different calcium-phosphate and fluoride based delivery vehicles on artificial caries like enamel lesions. J Dent. 2014;42(4):466-74. https://doi.org/10.1016/j.jdent.2013.12.017

10. Pignatelli I, Kumar A, Shah K, Balonis M, Bauchy M, Wu $B$ et al. Vertical scanning interferometry: a new method to quantify re-/de-mineralization dynamics of dental enamel. Dent Mater. 2016;32(10):e251-61. https://doi.org/10.1016/i.dental.2016.07.004

11. Fernández CE, Tenuta LMA, Cury JA. Validation of a cariogenic biofilm model to evaluate the effect of fluoride on enamel and root dentine demineralization. PLoS One. 2016;11(1):e0146478. https://doi.org/10.1371/journal.pone.0146478

12. Brambilla E, lonescu A, Cazzaniga G, Edefonti V, Gagliani M. The influence of antibacterial toothpastes on in vitro Streptococcus mutans biofilm formation: a continuous culture study. Am J Dent. 2014;27(3):160-6.

13. Oliveira PR, Fonseca AB, Silva EM, Coutinho TC, Tostes MA. Remineralizing potential of CPP-ACP crèmes with and without fluoride in artificial enamel lesions. Aust Dent J. 2016;61(1):45-52. https://doi.org/10.1111/adj.12305

14. Li F, Weir MD, Chen J, Xu HH. Comparison of quaternary ammonium-containing with nano-silver-containing adhesive in antibacterial properties and cytotoxicity. Dent Mater. 2013;29(4):450-61. https://doi.org/10.1016/i.dental.2013.01.012

15. Zhang N, Weir MD, Romberg E, Bai Y, Xu HH. Development of novel dental adhesive with double benefits of protein-repellent and antibacterial capabilities. Dent Mater 2015;31(7):845-54. https://doi.org/10.1016/i.dental.2015.04.013

16. Al-Mullahi AM, Toumba KJ. Effect of slow-release fluoride devices and casein phosphopeptide/amorphous calcium phosphate nanocomplexes on enamel remineralization in vitro. Caries Res. 2010;44(4):364-71. https://doi.org/10.1159/000316090
17. Souza CC, Cury JLM, Coutinho TCL, Silva EM, Tostes MA. Effect of different application frequencies of CPP-ACP and fluoride dentifrice on demineralized enamel: a laboratory study. Am J Dent. 2014;27(4):215-9.

18. Arends J, Bosch JJ. Demineralization and remineralization evaluation techniques. J Dent Res. 1992;71(Sp No):924-8.

19. Karlinsey RL, Mackey AC, Stookey GK, Pfarrer AM. In vitro assessments of experimental $\mathrm{NaF}$ dentifrices containing a prospective calcium phosphate technology. Am J Dent. 2009;22(3):180-4.

20. Pulido MT, Wefel JS, Hernandez MM, Denehy GE, Guzman-Armstrong S, Chalmers JM et al. The inhibitory effect of MI paste, fluoride and a combination of both on the progression of artificial caries-like lesions in enamel. Oper Dent. 2008;33(5):550-5. https://doi.org/10.2341/07-136

21. Kumar VL, Itthagarun A, King NM. The effect of casein phosphopeptide-amorphous calcium phosphate on remineralization of artificial caries-like lesions: an in vitro study. Aust Dent J. 2008;53(1):34-40. https://doi.org/10.1111/j.1834-7819.2007.00006.x

22. Hamba H, Nikaido T, Inove G, Sadr A, Tagami J. Effects of CPP-ACP with sodium fluoride on inhibition of bovine enamel demineralization: a quantitative assessment using micro-computed tomography. J Dent. 2011;39(6):405-13. https://doi.org/10.1016/i.jdent.2011.03.005

23. Oliveira GMS, Ritter AV, Heymann HO, Swift E, Donovan T, Brock $G$ et al. Remineralization effect of CPP-ACP and fluoride for white spot lesions in vitro. J Dent. 2014;42(12):1592-602. https://doi.org/10.1016/i.jdent.2014.09.004

24. Baroni C, Marchionni S, Bazzocchi MG, Cadenaro M, Nucci C, Manton DJ. A SEM and non-contact surface white light profilometry in vivo study of the effect of a crème containing CPP-ACP and fluoride on young etched enamel. Scanning. 2014;36(2):270-7. https://doi.org/10.1002/sca.21102.

25. Ten Cate JM, Duijsters PP. Influence of fluoride in solution on tooth demineralization. II. Microradiographic data. Caries Res. 1983;17(6):513-9. https://doi.org/10.1159/000260711

26. Featherstone JDB. Prevention and reversal of dental caries: role of low level fluoride. Community Dent Oral Epidemiol. 1999;27(1):31-40. https://doi.org/10.1111/i.1600-0528.1999.tb01989.x

27. Featherstone JD. Remineralization, the natural caries repair process - the need for new approaches. Adv Dent Res. 2009;21(1):4-7. https://doi.org/10.1177/0895937409335590

28. Zhang Q, Xou J, Yang R, Zhou X. Remineralization effects of casein phosphopeptide-amorphous calcium phosphate crème on artificial early enamel lesions of primary teeth. Int J Paediatric Dent. 2011;21(5):374-38. https://doi.org/10.1111/j.1365-263X.2011.01135.x

29. Exterkate RAM, Crielaard W, Ten Cate JM. Different response to amine fluoride by Streptococcus mutans and polymicrobial biofilms in a novel high-throughput active attachment model. Caries Res. 2010;44(4):372-9. https://doi.org/10.1159/000316541 